\title{
An In Vitro Comparison of the Forces Released by Closed Nickel-Titanium Springs
}

\author{
Débora FC Carvalho ${ }^{1}$, Victor TL Vieira ${ }^{2}$, Renata Castro $^{3}$, Luciana B Oliveira ${ }^{4}$
}

\begin{abstract}
Aim: The aim of this study was to evaluate the force-release behavior of closed coil nickel-titanium springs of three different commercial brands available on the market, as well those from different batches, tested over multiple distances, according to the number of deactivations. Materials and methods: For this in vitro analysis, closed coil nickel-titanium springs of the following numbers and brands: eight, 3 mm GAC ${ }^{\circledR}$ springs; eight, $3 \mathrm{~mm}$ springs from TP Orthodontics ${ }^{\circledR}$ and eight, $5 \mathrm{~mm}$ springs from MORELLI ${ }^{\circledR}$ were standardized at $200 \mathrm{gf}$ force. Two batches of all three brands were tested and compared. All springs were evaluated on a test machine and extended to a distance of five times beyond their original length. The springs were extended, and the distances of force released were measured and marked at every $20 \%$ of the total spring length, during their deactivation, and the process was repeated five times for each spring.

Results: The intraclass correlation coefficients showed that the value of $200 \mathrm{gf}$ indicated by the manufacturers was poorly reproduced. The springs did not change their force release after successive extensions. All springs presented higher deactivation force values as their stretching increased. Conclusion: All springs presented the greater release of force as their stretch was increased, but the GAC ${ }^{\circledast}$ brand springs presented a more uniform pattern. TP Orthodontics ${ }^{\oplus}$ springs exhibited an acceptable force release pattern, but MORELLI ${ }^{\circledR}$ springs proved to be far below expected strength. Clinical significance: As a clinical consideration of the study, the results obtained in the present research are relevant to the use of nickeltitanium closed springs with regard to the quantity of force released during the mechanics of space closure after extraction (main application of nickel-titanium closed springs), and to the pattern of forces released by springs in view of the real context of gradual closure of spaces after tooth extractions.
\end{abstract}

Keywords: Biomechanics, NiTi, Orthodontics.

The Journal of Contemporary Dental Practice (2019): 10.5005/jp-journals-10024-2703

\section{INTRODUCTION}

The methods for space closure during orthodontic mechanics may be influenced by the characteristics of the accessories, and by the training and clinical experience of the professional. ${ }^{1}$ Nickel-titanium springs are among the options of orthodontic accessories for space closure. With the use of nickel-titanium super elastic closed springs, ideally, there should hardly be any reduction in force during tooth movement, because the properties of the springs should remain unchanged during the entire time of use. ${ }^{2}$

However, some authors ${ }^{3}$ have affirmed that the springs fail to exhibit constant release of deactivation forces based on in vitro tests performed by traction of nickel-titanium closed springs of the GAC brand, which had one immediate measurement and another after 4 weeks. This showed a distinct reduction in the force released by the springs between the first and second measurements.

Other researchers, ${ }^{4}$ after performing traction tests involving 14 commercial brands of nickel-titanium closed springs with standardized measurements in millimeters, found that the forces released by the springs were extremely variable; some of the springs tested generated inconsistent and inconstant forces during deactivation. Another in situ study evaluated the changes in the reduction of force of nickel-titanium closed springs after clinical use and compared their results with those obtained with springs that only went through laboratory tests, without previous clinical use. There was no statistical difference between the two evaluations, however, the springs underwent loss of approximately $12 \%$ of their initial force, after 4 weeks of intraoral use, an additional drop of $7 \%$ between 4 weeks and 8 weeks of use and stabilization of the forces after this period. ${ }^{5}$ Finally, even reactivation of the springs
${ }^{1,3}$ Division of Orthodontics, Faculdade São Leopoldo Mandic, Instituto de Pesquisas São Leopoldo Mandic, Campinas, Brazil

${ }^{2}$ Unigranrio University, Rio de Janeiro, Rio de Janeiro, Brazil

${ }^{4}$ Division of Pediatric Dentistry, Faculdade São Leopoldo Mandic, Instituto de Pesquisas São Leopoldo Mandic, Campinas, Brazil

Corresponding Author: Luciana B Oliveira, Division of Pediatric Dentistry, Faculdade São Leopoldo Mandic, Instituto de Pesquisas São Leopoldo Mandic, Campinas, Brazil, Phone: +55 19 3211-3608, e-mail: lubutini@uol.com.br

How to cite this article: Carvalho DFC, Vieira VTL, Castro R, et al. An In Vitro Comparison of the Forces Released by Closed NickelTitanium Springs. J Contemp Dent Pract 2019;20(12):1380-1383.

Source of support: Nil

Conflict of interest: None

during clinical use was considered not recommendable, because the springs underwent degradation of their superelastic properties, changes in the forces released and diminished elastic recovery. ${ }^{6}$

A previous study ${ }^{4}$ drew attention to the analysis of the catalog of numerous commercial brands, which highlighted distinct terms on their packages, such as "ultralight", "light", "medium", "heavy", and "extra heavy", or listed "constant force values" such as "100 gf", "150 gf", and "200 gf", and even identified the springs by the diameter of the lumen, such as "0.010", "0.011" and "0.012". However, possible biases of previous studies ${ }^{2,3}$ were found in the performance of traction tests to obtain the forces released by the springs, with a lack of attention to, and questions about these terms. Furthermore, there is no comparison of the results of studies 
with these standardized force values provided on the labels by the manufacturers. Moreover, springs with lower "force values" are more frequently used for tests, because they (the manufacturers) almost always associated the use of the spring with the clinical retraction of canines in cases of tooth extraction. ${ }^{6}$ These data on the labels of springs may confuse the clinical understanding of orthodontists and lead to questions about whether, when using a spring with a certain standardization of force, this force would be released in a constant manner, irrespective of the activation distance and the quantity of activations of the spring used, as well as the commercial brand selected for the treatment.

Based on the foregoing, the present research aimed to evaluate the standardization of the manufacturers, and the replicability of the deactivation force values disclosed by the manufacturers of nickeltitanium closed springs, by means of comparison between lots of the same commercial brand, and between different commercial brands of springs available on the market. In addition, due to the demand for clinical reactivations during orthodontic mechanics, the authors intended to evaluate, by means of successive activations, whether changes occurred in the forces released by the springs. Recording the forces released by the springs over the course of different distances in millimeters is pertinent, due to the proximity of this method to the clinical reality, within the context of gradual closure of the spaces created after tooth extractions.

\section{Materials and Methods}

\section{Sample Preparation and Selection}

To conduct this in vitro study, 24 nickel-titanium superelastic springs with $200 \mathrm{~g}$ of force were randomly selected. Three different commercial brands ${ }^{7}$ were tested: eight springs, $\mathrm{GAC}^{\oplus}$ (GAC International Inc.) (Fig. 1A), eight springs, TP Orthodontics ${ }^{\oplus}$ (Reflex ${ }^{\oplus}$ Closed Coil Spring, TP Orthodontics Inc.) (Fig. 1B), and eight springs, MORELLI ${ }^{\circledast}$ (Dental Morelli Ltda, Sorocaba, BR) (Fig. 1C) these were from two different lots of the each brand, with four springs in each lot (Table 1). To perform the tests, hooks were fabricated of $1.00 \mathrm{~mm}$ steel wire for adapting the springs to the test machine. Different methods were adopted for verifying the forces released by the springs. All the springs were extended up to five times their passive length because this quantification refers to the maximum extension informed by the manufacturer's catalog. So that, the springs of TP Orthodontics ${ }^{\circledR}$ and $\mathrm{GAC}^{\circledR}$ presented $3 \mathrm{~mm}$; and those of MORELLI ${ }^{\oplus}$ presented an active part of $5 \mathrm{~mm}$; their maximum extensions attained were $15 \mathrm{~mm}$ and $25 \mathrm{~mm}$, respectively. Points for verification ${ }^{8}$ of the forces released by the springs were marked at every $20 \%$, of the extension of the springs, by means of the test machine software (EMIC DL 200 MF-Instron ${ }^{\oplus}$, São José dos Pinhais,
SP, Brazil). ${ }^{4}$ The entire process of extension and verification of the forces released by the springs was repeated five-time for each spring tested. The methodology proposed in the present study had previously been adopted in the studies of Bezrouk et al. ${ }^{2}$ and Maganzini et al. ${ }^{4}$

The nickel-titanium closed springs were evaluated by means of traction forces in a universal test machine EMIC DL 200 MF (Instron ${ }^{\circledR}$, São José dos Pinhais, SP, Brazil) programmed with a speed of $10 \mathrm{~mm} /$ minute. Data analyses and collection were obtained by means of the software Tesc version 3.04 (EMIC, Curitiba/PR, Brazil). ${ }^{4}$

\section{Statistical Analysis}

To verify the replicability of the deactivation force values between the two lots of springs tested, intraclass correlation coefficients were applied. These same tests were used to verify whether the deactivation forces obtained with the different brands of springs replicated the $200 \mathrm{gf}$ indicated by the manufacturers.

To compare the effect of the brand of spring, number of deactivations and condition of extension/stretching, and the interaction of these factors on the deactivation force values, the data were submitted to three-way analysis of variance for repeated measures. The multiple comparisons were made with the Tukey test.

The statistical calculations were made in the program SPSS 23 (SPSS Inc., Chicago, IL, USA), adopting the level of significance of $5 \%$.

\section{RESULTS}

When the deactivation force values were compared between the two lots of springs of each of the brands evaluated, by means of the intraclass correlation coefficient (ICC), the authors observed that for the GAC (ICC = 0.982), TP $($ ICC = 0.904), and Morelli $(I C C=$ $0.950)$ springs, the replicability was excellent. That is, the values obtained with both lots presented agreement at an excellent level. Therefore, for proceeding with the analyses, the data of only one of the lots were used.

Three-way analysis of variance for repeated measures revealed that there was no statistically significant interaction between

Table 1: Specifications of springs used in the study

\begin{tabular}{|c|c|c|c|}
\hline $\begin{array}{l}\text { Spring/ } \\
\text { Manufacturer }\end{array}$ & $\begin{array}{l}\text { Length } \\
\text { (without rings) }\end{array}$ & Lots evaluated & $\begin{array}{l}\text { City/State/ } \\
\text { Country }\end{array}$ \\
\hline $\mathrm{GAC}^{\circledast}$ & $3 \mathrm{~mm}(200 \mathrm{gf})$ & A4Y2/B443 & $\begin{array}{l}\text { Bohemia, NY, } \\
\text { USA }\end{array}$ \\
\hline & \multirow[t]{2}{*}{$3 \mathrm{~mm}$ (200 gf) } & 028140B2KSM & \multirow{2}{*}{$\begin{array}{l}\text { La Porte, } \\
\text { Indiana, USA }\end{array}$} \\
\hline Orthodontics $^{\circledR}$ & & $11018087 \mathrm{KSM}$ & \\
\hline MORELLI ${ }^{\otimes}$ & $5 \mathrm{~mm}(200 \mathrm{gf})$ & $2051092 / 2073908$ & $\begin{array}{l}\text { Sorocaba, São } \\
\text { Paulo, Brazil }\end{array}$ \\
\hline
\end{tabular}

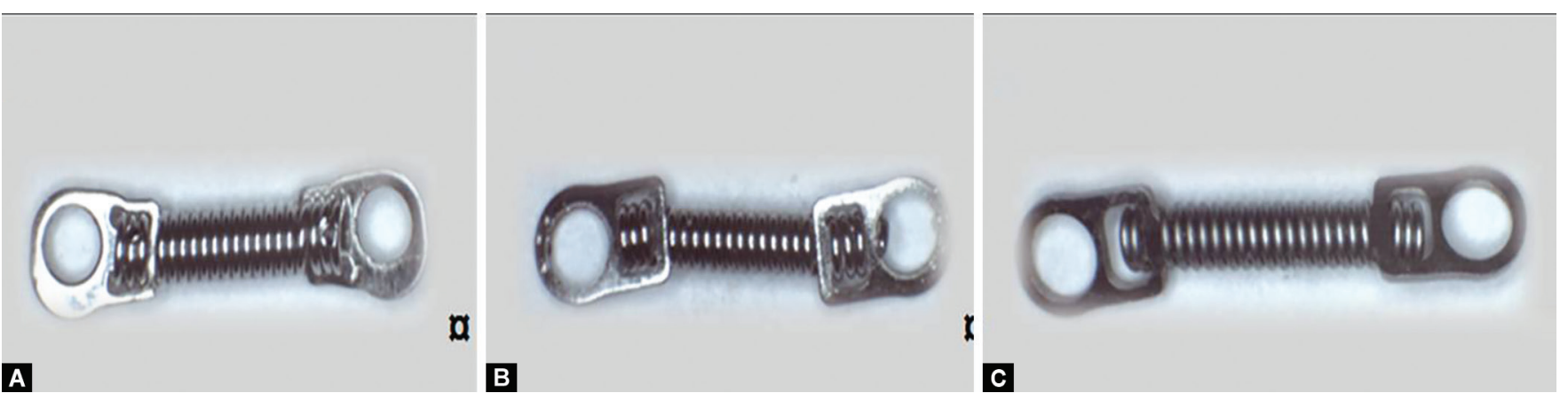

Figs 1 A to $C$ : (A) GAC ${ }^{\circledR}$ spring; (B) TP Orthodontics ${ }^{\oplus}$; (C) MORELLI ${ }^{\circledR}$ spring 
Table 2: Means and standard deviation of spring deactivation force values (gf), according to brand and condition of extension, irrespective of number of deactivations performed

\begin{tabular}{llll}
\hline & \multicolumn{3}{c}{ Spring brand } \\
\cline { 2 - 4 } Extension (\%) & $\mathrm{GAC}$ & $\mathrm{TP}$ & Morelli \\
\hline 20 & $135.45(5.95)$ & $99.16(11.73)$ & $103.19(3.30)$ \\
& $\mathrm{Ab}$ & $\mathrm{Aa}$ & $\mathrm{Aa}$ \\
40 & $149.27(5.52)$ & $172.79( \pm 6.37)$ & $111.84(3.45)$ \\
& $\mathrm{Ab}$ & $\mathrm{Bc}$ & $\mathrm{Aa}$ \\
60 & $177.74(4.38)$ & $213.58(5.44) \mathrm{Cc}$ & $118.48(3.24)$ \\
& $\mathrm{Bb}$ & & $\mathrm{Aa}$ \\
80 & $234.79(6.48)$ & $262.30(7.99) \mathrm{DC}$ & $173.92(9.37) \mathrm{Ba}$ \\
& $\mathrm{Cb}$ & & \\
100 & $346.28(13.97)$ & $359.86(13.85)$ & $356.18(27.15)$ \\
& $\mathrm{Da}$ & $\mathrm{Ea}$ & $\mathrm{Ca}$ \\
\hline
\end{tabular}

Means followed by different capital letters indicate statistically significant difference between the force values within each column. Means followed by different lower case letters indicate statistically significant difference between the force values within each line

the brand of spring, number of deactivations, and condition of extension ( $p=1.000$ ). Not even in isolation did the number of deactivations present statistically significant influence $(p=0.098)$ on the deactivation force of the springs. Whereas, the interaction between the brand of spring and condition of an extension was shown to be significant from the statistical point of view $(p<0.001)$.

Table 2 shows the means and standard deviation of spring deactivation force values ( $\mathrm{gf}$ ), according to the brand and condition of extension, irrespective of number of deactivations performed. When making the multiple comparisons by the Tukey test, the TP springs were found to present higher deactivation force values as their extension was increased. Except for the fact that there was no statistically significant difference between the conditions under which the springs were extended at $20 \%$ and $40 \%$, the GAC springs demonstrated the same performance as that of the TP springs. On the contrary, for the Morelli springs, there was no statistically significant difference between the forces obtained up to $60 \%$ extension; as from this point, the deactivation force values increased progressively. In addition, the Tukey test indicated that under an extension of $20 \%$, there was no statistically significant difference between the TP and Morelli springs as regards forces, which provided statistically lower values than those obtained when the GAC springs were used. Under the conditions in which the springs were extended up to $40 \%, 60 \%$, or $80 \%$, the TP springs provided higher force values, while the lower values resulted from the use of the Morelli springs. The GAC springs released intermediate forces of 149.27 (5.52) gf, $177.74(4.38) \mathrm{gf}$, and 234.79 (6.48) $\mathrm{gf}$ when extended up to $40 \%, 60 \%$, and $80 \%$, respectively. Whereas when $100 \%$ extension was performed, there were no statistically significant differences among the brands of springs.

\section{Discussion}

Among the three commercial brands of nickel-titanium closed springs studied $\left(\mathrm{GAC}^{\oplus}\right.$, TP Orthodontics ${ }^{\circledR}$, and MORELLI $\left.{ }^{\circledR}\right)$; none presented difference in the pattern of force released, between the two lots tested. This is expected of manufacturers in general, because standardization is essential for the trust in any device used in the clinical routine of orthodontists. However, a previous study ${ }^{5}$ that focused on laboratory evaluation of only springs of the $\mathrm{GAC}^{\oplus}$ brand, both without prior clinical use and after clinical use, found significant differences in the levels of force released even between the springs of the same manufacturing lot. But bearing in mind the impact that these differences in the levels of force released by springs could cause on the monthly rate of space closure for which they were being used, and irrespective of any other factor, this rate was of $1 \mathrm{~mm}$ per month.

In the present study, the samples selected presented a description of force release of $200 \mathrm{gf}$ made by the manufacturers, however, all the brands of springs poorly reproduced the value indicated. This finding has also been shown by other authors ${ }^{4}$ who affirmed that it was improbable that any spring could exhibit a certain constant force over all the distances of deactivation, and that the manufacturers should replace the commercial terms such as "ultralight", "light", "medium", "heavy", and "extra heavy". One of the studies, ${ }^{4}$ evaluated a large quantity of different brands of springs (14 brands) with five springs of each brand, totaling seventy springs, and these presented a great variance in the quantity of force released during the deactivation process (147-474 gf), however, although the study had standardized the length in millimeters of the springs $(9 \mathrm{~mm})$, it did not inform the force which according to the manufacturer, the springs should release.

Bearing in mind that closure of space of a premolar extraction, which is the most common indication for the use of nickel-titanium closed springs of approximately $7 \mathrm{~mm}$ and that the ideal force for

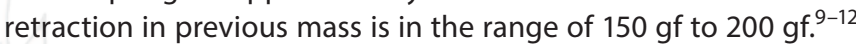
Only the force values recorded during the extension of $40 \%$ and $20 \%$ of the springs in this study could be considered parameters for comparison within a possible clinical reality.

Previous knowledge about nickel-titanium closed springs ${ }^{13}$ is that their clinical application is very easy because they allow the treatment with activation of the device only once. However, the results of the present study showed that to attain the quantity of force disclosed by the manufacturers some intervention would be necessary, which would generally involve the reactivation or replacement of the spring, and this was due to the fact of the springs having poorly replicated the value of force indicated by the manufacturers. In contrast, nickel-titanium springs have been shown to be superior to the use of other devices such as chain elastics or springs with other chemical compositions. ${ }^{14-17}$

However, the authors verified that the number of deactivations showed no statistically significant influence on the deactivation force of the springs evaluated, which corroborated the findings of another study ${ }^{2}$ that submitted the springs to cycles of extension and returned under the same conditions, and the springs were also left without load between the consecutive cycles. Although the study used different speeds of extension, the authors did not find any change in the degree of force degradation of the springs after successive extensions. Added to this situation, there are authors, ${ }^{6}$ who have proved (by means of laboratory studies with 50 springs of the GAC brand, evaluating them before and after 6 months of clinical use) that there are changes in the forces and reduction in superelastic recovery after this period of clinical use of the springs.

The interaction between the brand of spring and condition of extension was shown to be the only significant interaction from the statistical point of view in this study. All the brands of springs presented higher deactivation force values as their extension was increased, with the springs of the $\mathrm{GAC}^{\circledR}$ presenting the most uniform pattern (Table 2). This was found by authors ${ }^{4}$ who also verified significantly variable forces released by springs at different distances $(12,9,6$, and $3 \mathrm{~mm})$. 
In the comparison of the three brands under extension of $20 \%$, there was no difference between the TP and Morelli springs as regards forces, which provided statistically lower values than those obtained when the GAC springs were used. Under the conditions in which the springs were extended up to $40 \%$ and $60 \%$, the $\mathrm{TP}^{\oplus}$ springs provided higher force values, while the lower values resulted from the use of the MORELLI ${ }^{\circledR}$ springs. Statistical differences among these and other brands of nickel-titanium closed springs were also found in another previous study, ${ }^{7}$ in which different brands of springs were tested and compared, and even when submitted to laboratory conditions of oral temperature simulation, with standardization of the size of springs, they also presented statistical differences among them as regards the mean force released by the springs. There are probably molecular differences in the alloys of the springs, and analyses with graphs of phase transformation of the crystallographic structure of the nickel-titanium alloys between the martensitic and austenitic phases have been suggested to explain the behavior of the alloy of each of the springs. ${ }^{18-21}$

As a clinical consideration of the study, the results obtained in the present research are relevant to the use of nickel-titanium closed springs with regard to the quantity of force released during the mechanics of space closure after extraction (main application of nickel-titanium closed springs), and to the pattern of forces released by springs in view of the real context of gradual closure of spaces after tooth extractions.

\section{Conclusion}

All the brands of nickel-titanium closed springs evaluated in this study poorly reproduced the value of $200 \mathrm{gf}$ indicated by the manufacturers, and the TP Orthodontics ${ }^{\circledR}$ brand of spring most approximated this value in the clinically applicable extensions. Reactivation of the springs was shown to be variable, bearing in mind that they do not undergo change in the release of forces after successive extensions.

All the springs showed higher force release values as their extension was increased, but the springs of the $\mathrm{GAC}^{\otimes}$ brand showed the most uniform pattern. The TP Orthodontics ${ }^{\circledR}$ springs exhibited an acceptable pattern of force release, however, the spring of the MORELLI ${ }^{\circledR}$ brand was shown to be very short of the force expected.

\section{References}

1. Barlow M, Kula K. Factors influencing efficiency of sliding mechanics to close extraction space: a systematic review. Orthod Craniofac Res 2008;11(2):65-73. DOI: 10.1111/j.1601-6343.2008.00421.x.

2. Bezrouk A, Balsky L, Smutny M, et al. Thermo-mechanical properties of NiTi closed coil springs-force degradation and force regeneration over time, viscous properties. Acta Medic 2013;56(2):41-46. DOI: 10.14712/18059694.2014.22.
3. Manhartsberger C, Seidenbusch W. Force delivery of Ni-Ti coil springs. Am J Orthod Dentofac Orthop 1996;109(1):8-21. DOI: 10.1016/S08895406(96)70158-0.

4. Maganzini AL, Wong AM, Ahmed MK. Forces of various nickel titanium closed coil springs. Angle Orthod 2010;80(1):182-187. DOI: 10.2319/011509-592.1.

5. Cox C, Nguyen T, Koroluk L, et al. In vivo force decay of nickel-titanium closed-coil springs. Am J Orthod Dentofac Orthop 2014;145(4): 505-513. DOI: 10.1016/j.ajodo.2013.12.023.

6. Magno AF, Monini ADC, Capela MV, et al. Effect of clinical use of nickeltitanium springs. Am J Orthod Dentofac Orthop 2015;148(1):76-82. DOI: 10.1016/j.ajodo.2015.02.028.

7. Alavi S, Yaghchie M. Force characteristics of nickel titanium closed coil springs. J Dent Res 2006;3(5):77-83.

8. Momeni Danaei S, Oshagh M, Khozaei A. Effect of recycling and autoclave sterilization on the unloading forces of NiTi closed-coil springs: an in vitro study. J Dent 2013;14(4):184-190.

9. Smith R, Storey E. The importance of force in orthodontics. Aust Dent J 1952;56:291-304.

10. Reitan K. Clinical and histologic observation on tooth movement during and after orthodontic treatment. Am J Orthod 1967;53(10): 721-745. DOI: 10.1016/0002-9416(67)90118-2.

11. Ricketts RM. The wisdom of the bioprogressive philosophy. Semin Orthod 1998;4(4):201-209. DOI: 10.1016/S1073-8746(98)80025-X.

12. Proffit WR, Fields HW. Princípios mecânicos no controle da força ortodôntica. In Proffit WR, Fields HW, ed. Ortodontia Contemporânea, 3a ed., Rio de janeiro: Guanabara Koogan; 2002; pp. 307-309.

13. Wichelhaus A, Brauchli L, Ball J, et al. Mechanical behavior and clinical application of nickel-titanium closed-coil springs under different stress levels and mechanical loading cycles. Am J Orthod Dentofac Orthop 2010;137(5):671-678. DOI: 10.1016/j.ajodo.2008.06.029.

14. Han S, Quick DC. Nickel-titanium spring properties in a simulated oral environment. Angle Orthod 1993;63(1):67-72. DOI: 10.1043/0003-3219(1993)063<0067:NSPIAS>2.0.CO;2.

15. Samuels RHA, Rudge SJ, Mair LH. A comparison of the rate of space closure using a nickel-titanium spring and an elastic module: a clinical study. Am J Orthod Dentofac Orthop 1993;103(5):464-467. DOI: 10.1016/S0889-5406(05)81798-6.

16. Von Fraunhofer JA, Bonds PW, Johnson BE. Force generation by orthodontic coil springs. Angle Orthod 1993;63(2):145-148. DOI: 10.1043/0003-3219(1993)063<0145:FGBOCS>2.0.CO;2.

17. Pires BU, de Souza RE, Filho MV, et al. Force degradation of different elastomeric chains and nickel titanium closed springs. Braz J Oral Sci 2011;10(3):167-170.

18. Tripolt $\mathrm{H}$, Burstone $\mathrm{CJ}$, Bantleon $\mathrm{P}$, et al. Force characteristics of nickel-titanium tension coil spring. Am J Orthod Dentofac Orthop 1999;115(5):498-507. DOI: 10.1016/S0889-5406(99)70271-4.

19. Langeron T, Filleul MP, Van Humbeeck J. Characterization of closed nickel-titanium orthodontic coil springs. J Phys 2001;11:565-570. DOI: 10.1051/jp4:2001894.

20. Vieira CIV, Caldas SGFR, Martins LP, et al. Superelastic and force plateau of nickel-titanium springs: an in vitro study. Dental Press $J$ Orthod 2016;21(3):46-55. DOI: 10.1590/2177-6709.21.3.046-055.oar.

21. Vieira CIV, Reis JMSN, Vaz LG, et al. Deformation of nickeltitanium closed coil springs: an in vitro study. Dental Press J Orthod 2017;22(1):38-46. DOI: 10.1590/2177-6709.22.1.038-046.oar. 